\title{
Penetrating knife wounds to the orbital region: A report of two cases
}

\author{
Rodrigo Liceaga Reyes ${ }^{1}$, Luis Manuel Bustos Aguilera ${ }^{2}$ and Luis Gerardo Fuenmayor García ${ }^{3}$ \\ ${ }^{1}$ Maxillofacial Surgery Department, Specialities Hospital, Campeche, México \\ ${ }^{2}$ Maxillofacial Surgery Department, General Hospital, Aguascalientes, México \\ ${ }^{3}$ Maxillofacial Surgery Department, General Hospital, Guadalajara, México
}

\begin{abstract}
Background: Penetrating knife injuries to the orbit are rare and infrequently reported. The orbit is a vulnerable area that provides access to the intracranial cavity, and a penetrating foreign object can injure eye, meninges and the central nervous system. The approach to treatment should be multidisciplinary, beginning with the trauma unit to provide airway maintenance and haemodynamic stabilization.
\end{abstract}

Objectives: The aim of the present was to describe and analyze penetrating knife injuries to the orbit, and discuss diverse types of orbital damage and treatments according to the kinematics of the trauma.

Materials and methods: It was a retrospective study, analysing 2 cases of penetrating knife injuries to the orbit reported at maxillofacial department.

Conclusions: Patients with knife penetrating wounds of the orbital region and orbital fractures are infrequent. The kinematics of traumatism, types of knife and force magnitude are fundamental factors to determine the damage produced by the knife and thus the treatment. Treatment should always be multidisciplinary and giving priority to vital structures and functions and the health of the ocular globe.

\section{Introduction}

Knife wounds to the maxillofacial region are infrequently reported; although they can be a significant life threat to the patient [1]. Orbital trauma is common in facial wounds and represents the second cause of blindness, making the health of the ocular globe a priority in cases of orbital wounds [2].

The orbit is a vulnerable area that provides access to the intracranial cavity, and a penetrating foreign object can injure meninges and the central nervous system. Orbitocraneal trauma has the highest mortality among other forms of maxillofacial trauma [3].

Triage states that the treatment of orbital fractures can be postponed until vital structures have been stabilized, usually calling for a multidisciplinary team [4]. We present two cases of knife wounds to the orbit, and discuss diverse types of orbital damage and treatments according to the kinematics of the trauma.

\section{Case reports}

\section{Case 1}

A 52 years old male patient presented to Maxillofacial Surgery Department, with a facial wound that had been inflicted by his 17 years old son with a kitchen knife an hour prior to his arrival. The patient himself, having been wounded on the right side of the face, retrieved the knife. He was stable, conscious and reported no changes in visual acuity of the right eye. On physical examination he presented ecchymoses, palpebral occlusion and an irregular wound in the right infraorbital region (Figure 1) without active bleeding. Ocular movements were normal and there was no apparent damage to the eye. A CT scan showed normal eye and muscle structures (Figures 2 and 3) and a pure blow blowout fracture of the orbital floor (Figure 4). The patient had brought with him the kitchen knife he had been assaulted with, (Figure 5) which had a curved blade, and he reported that the concave surface was facing downwards when he removed it. Soft tissues were explored, cleansed and sutured under local anesthetic. The blowout fracture was

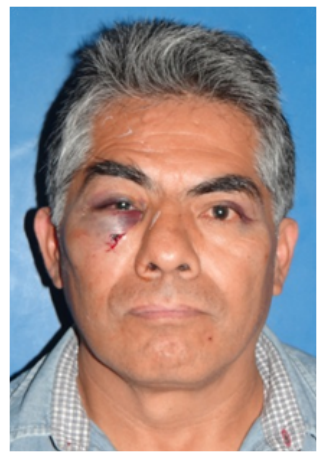

Figure 1. Frontal view of the patient, with an irregular infraorbital wound, ecchymoses and palpebral occlusion.

Correspondence to: Rodrigo Liceaga Reyes, General Hospital of Specialties "Dr Javier Buenfil Osorio" Secretary of Health, Av. Lazaro Cárdenas \#308, Campeche, México, Tel: +521 5585786138; E-mail: r_liceaga@hotmail.com

Key words: knife wounds, orbital blowout fracture, penetrating injuries, maxillofacial region

Received: November 21, 2016; Accepted: December 16, 2016; Published: December 19, 2016 


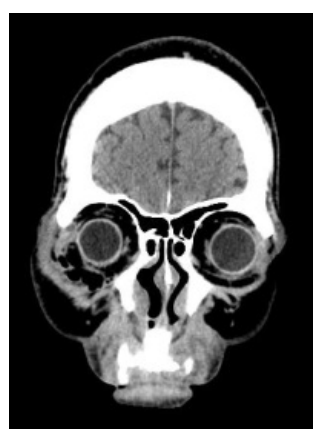

Figure 2. CT shows normal eye.

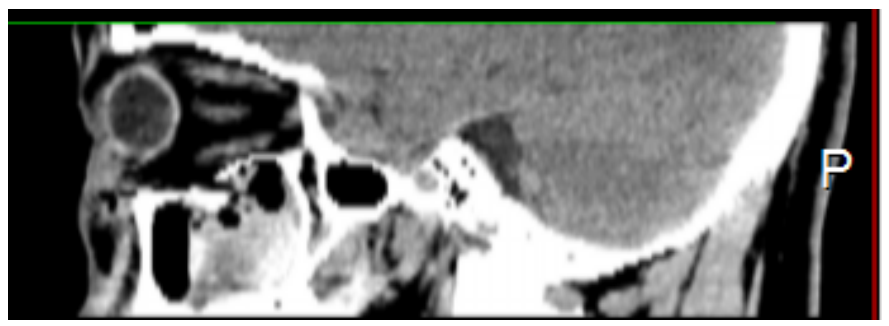

Figure 3. No damaged to the inferior rectus muscle.

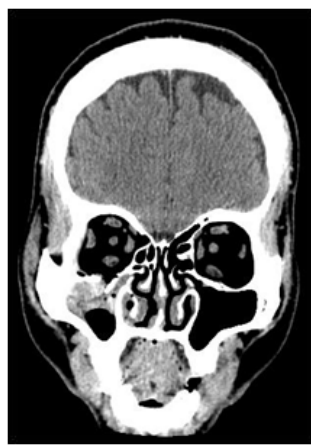

Figure 4. Pure blowout fracture of the orbital floor.

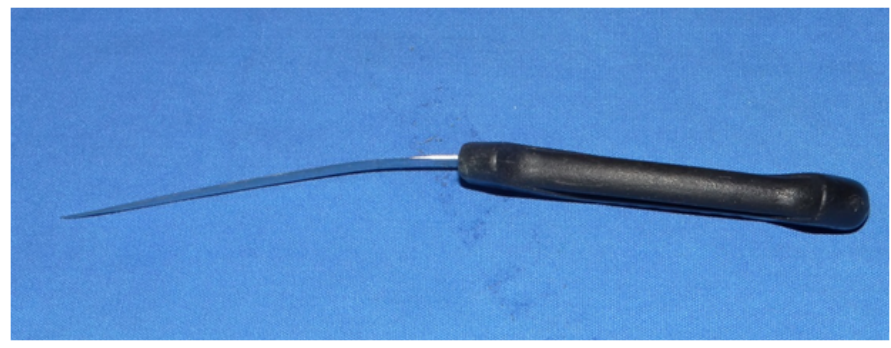

Figure 5. Kitchen knife the patient had been assaulted with which had a curved blade.

treated in a conservative manner. The patient was given antitetanus prophylaxis, antibiotics and discharged.

\section{Case 2}

A 58 years old male was brought in to Maxillofacial Surgery Department, conscious, stable and who reported having been attacked and injured in the eye with a knife, half an hour before admission. He presented a wound to the conjunctiva of the lower eyelid (Figures 6 and 7). A CT scan showed a penetrating wound to the right ocular globe (Figure 8) and an impure blowout fracture of the orbital floor (Figure 9). The Ophthalmology department performed evisceration of the right ocular globe. Setting of the orbital fractures and osteosynthesis



Figure 6. Frontal view of the patient, ecchymoses and palpebral occlusion, no facial wound visible

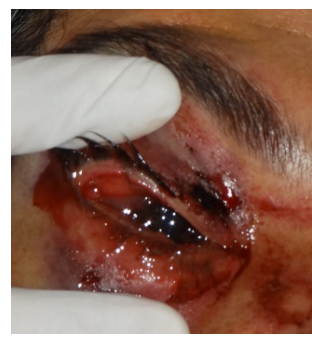

Figure 7. Ocular globe wound.



Figure 8. CT showed a penetrating wound to the right ocular globe.



Figure 9. Impure blowout facture of the orbital floor and infraorbital rim

was placed and the wound was used to treat the fractures as a transconjunctival approach. The patient was given antitetanus prophylaxis, antibiotics and discharged two days later.

\section{Discussion}

Knife wounds to the maxillofacial region are infrequently reported in the literature. Cohen and Boyer-Varley, in 1986, reported a sample 
of 37 patients with penetrating wounds to the maxillofacial region of which only 4 were caused by knives [5]. Grobbelaar and Knottenbelt reported a series of 11 patients [6]. Hudson, in 1992, reported in South Africa 4 episodes in a 4 -year period and Shinoshara et al presented 2 cases. The most recent literature presents a more statistically significant sample of 24 cases of knife wounds to the maxillofacial region of which none reported vascular damage or mortality, with rapid recovery and without adverse events $[1,7,8]$. There are scarce reports of knife wounds to the maxillofacial region and even less of orbital wounds orbit with fracture and ocular damage like the cases here reported.

In 1972 Jett et al evaluated the socioeconomic pattern of victims with penetrating knife and gunshot wounds [9].The typical patient was male, 15 to 35 years old, drug user and from a low socioeconomic level. Incidents occurred usually on Friday or Saturday between 9 pm -2 am and caused by domestic disputes. Our cases coincide partially since both patients are male, low socioeconomic level, only one corresponded to a domestic dispute and another to an assault, our patients were older, the incidents occurred on weekdays and there was no history of drug or alcohol use in the victims.

Usually, patients with knife wounds of the maxillofacial region present wounds to the thoracic and abdominal areas and cuts on the hands in an intent to defend themselves. This explains the low incidence of knife wounds to the face, since the hands protect it [1]. Our cases did not present wounds in other parts of the body.

Orbital fractures can be classified in two main groups: pure and impure [2]. One of our cases corresponded to a pure and the other to an impure fracture. The physical mechanisms of orbit fractures are subject of controversy. Most fractures occur behind the orbit rim and there is no direct contact of the bony walls with an external object, therefore they are considered indirect fractures [10-12]. In a few cases, such as the ones we report, an external object directly causes the orbital fracture. Oculocardiac reflex was not seen in either case [13]. Harris et al defined, in 1988, the Jael Syndrome as a penetrating knife wound of the maxillofacial region [14].

Most of the lesions resulting from domestic violence occur on the face and predominantly on the left side [15]. Our first patient was injured as a result of domestic violence while the second was assaulted, and both presented don the right side of the face.

The magnitude of force with which the knife impacts itself in the body is determinant for measuring the damage caused. A low level of force may be associated with skin and soft tissue penetration, while a moderate force is required to penetrate cartilage or a rib. A severe force is needed to penetrate dense bone. We consider that a moderate force was used in both of our cases since the fractured orbital structures are thin [16].

The knives commonly used in homicides and assaults are those available to the general population, such as domestic knives [16]. In Case 1 the knife used was a kitchen knife. In Case 2, the type of knife used was unknown. The geometry and shape of the point of the knife are the most relevant for the wound [17].

It is possible to differentiate between the kinematics of knife attacks: over and under the shoulder [18]. The speed of the knife as it enters the skin is approximately $7-10 \mathrm{~m} / \mathrm{s}$, although impacts at a slower speed may cause cranial wounds [19]. According to the biomechanics of a knife attack, forces of $2000 \mathrm{~N}$ and $70 \mathrm{~J}$ of energy can be produced [20].

In the first case the angle of the knife and the direction of the attack were determinant in not causing ocular or cerebral injuries, and caused only a pure fracture of the orbit floor without diplopia, dystopia and with normal ocular movements, classification A [21]. In the second case, the kinematic of the knife caused an impure fracture of the orbit and a penetrating wound to the ocular globe.

The incidence of ocular wounds in relation to blow out fractures is reported to be 20 to $30 \%$, and most are minor wounds. Ocular lesions should not stand in the way of the repair of orbital fractures [2]. In the first case a primary treatment of the penetrating wounds and a conservative approach of the fracture was performed since there was no indication for surgical repair [22,23]. In the second case, the affected ocular globe was treated urgently and the orbital fracture was surgically repaired days later [24].

\section{Conclusion}

Concluding, knife penetrating wounds of the orbital region and orbital fractures are infrequent. The kinematics of traumatism, types of knife and force magnitude are fundamental factors to determine the damage produced by the knife and thus the treatment. Treatment should always be multidisciplinary and giving priority to vital structures and functions and the health of the ocular globe.

\section{Conflict of interest}

There are no conflicts of interest.

\section{References}

1. Shinohara EH, Heringer L, de Carvalho JP (2001) Impacted knife injuries in the maxillofacial region: report of 2 cases. J Oral Maxillofac Surg 59: 1221-1223. [Crossref]

2. Ellis E 3rd (2012) Orbital trauma. Oral Maxillofac Surg Clin North Am 24: 629-648 [Crossref]

3. de Santana Santos T, Avelar RL, Melo AR, de Moraes HH, Dourado E (2011) Curren approach in the management of patients with foreign bodies in the maxillofacial region. J Oral Maxillofac Surg 69: 2376-2382. [Crossref]

4. Piotrowski WP (1992) The primary treatment of frontobasal and midfacial fractures in patients with head injuries. J Oral Maxillofac Surg 50: 1264-1268. [Crossref]

5. Cohen MA, Boyes-Varley G (1986) Penetrating injuries to the maxillofacial region. $J$ Oral Maxillofac Surg 44: 197-202. [Crossref]

6. Grobbelaar A, Knottenbelt JD (1991) Retained knife blades in stab wounds of the face is simple withdrawal safe? Injury 22: 29-31. [Crossref]

7. Hudson DA (1992) Impacted knife injuries of the face. Br J Plast Surg 45: 222-224 [Crossref]

8. Meer M, Siddiqi A, Morkel JA, Janse van Rensburg P, Zafar S (2010) Knife inflicted penetrating injuries of the maxillofacial region: A descriptive, record-based study. Injury 41: 77-81. [Crossref]

9. Jett HH, Van Hoy JM, Hamit HF (1972) Clinical and socioeconomic aspects of 254 admissions for stab and gunshot wounds. J Trauma 12: 577-580. [Crossref]

10. King EF, Samuel E (1944) Fractures of the orbit. Trans Opthal Soc U K 64: 134-153. [Crossref]

11. Pfeiffer RL (1943) Traumatic enophthalmos. Arch Ophthalmol 30: 718-724.

12. Le Fort R (1901) Experimental study on fractures of the superior jaw. Rev Chir 23: 208-227.

13. Kim BB, Qaqish C, Frangos J, Caccamese JF Jr (2012) Oculocardiac reflex induced by an orbital floor fracture: report of a case and review of the literature. J Oral Maxillofac Surg 70: 2614-2619. [Crossref]

14. Harris AM, Wood RE, Nortjé CJ, Grotepass F (1988) Deliberately inflicted, penetrating injuries of the maxillofacial region (Jael's syndrome). Report of 4 cases. $J$ Craniomaxillofac Surg 16: 60-63. [Crossref]

15. Le BT, Dierks EJ, Ueeck BA, Homer LD, Potter BF (2001) Maxillofacial injuries associated with domestic violence. J Oral Maxillofac Surg 59: 1277-1283. [Crossref] 
16. Gilchrist MD, Keenan S, Curtis M, Cassidy M, Byrne G, et al. (2008) Measuring knife stab penetration into skin simulant using a novel biaxial tension device. Forensic $\mathrm{Sci}$ Int 177: 52-65. [Crossref]

17. Croft J, PSDB Body armour standards for UK Police: (2003) Part 3: Knife and spike resistance. Police Scientific Development Branch, UK.

18. Miller SA, Jones MD (1996) Kinematics of four methods of stabbing: a preliminary study. Forensic Sci Int 82: 183-190. [Crossref]

19. Horgan T, Gilchrist M (2003) The creation of three-dimensional finite element models for simulating head impact biomechanics. Int J Crashworthiness 8: 353-366.

20. Chadwick EK, Nicol AC, Lane JV, Gray TG (1999) Biomechanics of knife stab attacks. Forensic Sci Int 105: 35-44. [Crossref]
21. Matsunaga K, Asamura S, Morotomi T, Wada M, Wada Y, et al., (2011) Association between preoperative inferior rectus muscle swelling and outcomes in orbital blowout fracture. J Craniomaxillofac Surg 39: 509-514. [Crossref]

22. Motamedi MH (2007) Primary treatment of penetrating injuries to the face. J Oral Maxillofac Surg 65: 1215-1218. [Crossref]

23. Liss J, Stefko ST, Chung WL (2010) Orbital surgery: state of the art. Oral Maxillofac Surg Clin North Am 22: 59-71. [Crossref]

24. Kontio R, Lindqvist C (2009) Management of orbital fractures. Oral Maxillofac Surg Clin North Am 21: 209-220, vi. [Crossref]

Copyright: $@ 2016$ Reyes RL. This is an open-access article distributed under the terms of the Creative Commons Attribution License, which permits unrestricted use, distribution, and reproduction in any medium, provided the original author and source are credited. 